https://doi.org/10.48009/1_iis_2005_303-310

\title{
BREAKING DOWN THE BLOCKING BOUNDARY OF SEPARATED IS COURSES IN IS CURRICULUM: A CASE STUDY
}

\author{
Raymond Frost, Ohio University, frostr@ohio.edu \\ Jacqueline Pike, Ohio University, jp309901 @ohio.edu \\ Wayne Huang, Ohio University, huangw @ohio.edu
}

\begin{abstract}
This research paper reports a case study on revising IS curriculum in a large public university by combining two previously separated courses, systems analysis and design and database management systems, into an integrated course. Findings and discussion will center on how the two courses were revised and integrated, how the integrated course is delivered to students, key success factors for the curriculum revision, and students' attitudes towards and learning performance in the integrated course. The research findings of this case study can provide some valuable insights and suggestions to other IS educators in their efforts to revise current curricula to provide better and higher quality programs to students in the future.
\end{abstract}

Keywords: Integrated course, database, systems analysis and design, curriculum

\section{INTRODUCTION}

Most current information systems (IS) courses, if not all, are designed and taught separately with largely disconnected content in each course. Students learn unique and specialized knowledge and skills in different IS courses and frequently do not see the high-level links between the courses in the curriculum. As a result, students graduated from such programs may have difficulties tackling real business problems. Those real business problems may not be necessarily too complicated for the graduates, but they require integrated knowledge and skills that do not magically evolve in separated IS courses.

Practitioners in industry frequently give feedback to IS educators that no real business problems can be solved using the skills learned from one or more separated IS courses alone. The serious issue facing IS educators is how to provide IS students with the necessary skills to solve real business problems. More effective students entering the workforce could also help to diffuse the recent debate on whether IT really does matter to business.

Therefore, it is important for educators to revise current curricula to break down the blocking boundary that separates IS courses. Integrated courses lead to integrated knowledge, skills, and, ultimately, the ability to solve real business problems.

This research paper reports a case study on revising IS curriculum in a large public university by combining two previously separated courses, systems analysis and design and database management systems, into an integrated course. Findings and discussion will center on how the two courses were revised and integrated, how the integrated course is delivered to students, key success factors for the curriculum revision, and students' attitudes towards and learning performance in the integrated course. The research findings of this case study can provide some 
valuable insights and suggestions to other IS educators in their efforts to revise current curricula to provide better and higher quality programs to students in the future.

\section{LITERATURE REVIEW}

As discussed above, one of the current major challenges faced by university educators is that knowledge is fragmented, access to knowledge is not universal, and fragmented knowledge learned in university programs cannot provide necessary integrated skills for university graduates to solve complex real business problems in the future [7].

Therefore, it is necessary and important for university educators to examine how their degree programs can equip graduates with necessary integrated knowledge and skills to solve practical and complicated business problems and how university education, in general, can evolve to address society's real problems.

Revising program curriculum by integrating separated courses is not new to educators in some disciplines of universities such as in medicine, engineering, and science $[3,4,5]$, although it is relatively new in the IS field. After searching the Institute for Science Information (ISI) Web of Science Database, no paper on integrated learning was found in major IS journals.

The constructivist model of learning posits that there is no objective reality independent of a learner's mind [1]. Rather than transmitted, knowledge is created, or constructed, by each learner [6].

Based on the constructivist theory of learning, integrating IS courses may help students better understand the existing links and connections between the courses and thereby make them more likely to see the big picture. This in turn would help them better construct meanings from materials and concepts. Therefore, according to constructivist learning theory, integrating courses can help students learn better and more effectively.

The following case study will describe a more than one year experience of integrating two previously separated IS courses in a large public university based on prior relevant studies and the theory of constructive learning in education literature.

\section{CASE STUDY}

\section{Background for the Course Revision}

The MIS department had a set of extraordinary weekly meetings in the fall of 2003 to plan new directions for the department and to construct an integrated curriculum. The driving force was a precipitous drop in enrollment in the department that threatened the viability of the major. It was decided at those meetings that the most successful courses in terms of post graduation student feedback were the two courses offered as part of the senior year capstone experience. One of those courses has students work with a live client to design and develop a system. The focus of the course is on the Systems Development Life Cycle (SDLC). The other course explores conceptual topics in the discipline such as SCM, ERP, CRM, pervasive computing, and so forth. 
Students routinely commented that those were the first courses in which they understood how the concepts of the major all fit together. Interestingly, those two courses were being offered by the same professor and most students took them as a block.

It was decided at those meetings to attempt to flow down content and pedagogy from the two capstone courses to the rest of the courses in the major. The department began with the first course in the major with the challenge that if it could be done there then it could be done anywhere. At this school the first course is actually two courses that are part of the common business core. One of those courses has traditionally focused on computer skills while the other course has focused on IS concepts. Neither course had received much attention over the years from the senior faculty in the department.

The department began with the skills course. That course was transformed to incorporate the SDLC as a problem solving methodology [2]. The course received very positive feedback from the students. The next courses targeted are the subject of this paper-the systems analysis and design and database management systems courses. These courses had been co-requisites for a number of years but had always been taught by different faculty. The linkages between the courses were somewhat loose.

Fortunately, some of the MIS faculty had experience teaching integrated courses in the common business core. At either the sophomore or junior level all business students are required to take one term in which their entire load is an integrated experience team-taught by four faculty from different disciplines - one of which is MIS. That prior experience combined with the recent integrated delivery of the capstone courses meant that the culture of integration was already present in the department.

\section{Procedure for the Course Revision}

In the spring of 2004, working under a grant from the Microsoft Corporation, the faculty from both the database management systems course and the systems analysis and design course began independent efforts to bring their courses in line with the new department model. They were greatly assisted in those efforts by an extraordinary honors student who had taken both courses and understood the missing linkages. The missing linkages included lack of SDLC methodology in the database course, lack of a clear definition of where database design fits into the SDLC methodology in the systems analysis course, and a misalignment in programming depth between both courses. The misalignment in program depth stemmed largely from the database course focusing on the visual integrated development environment (IDE) whereas the systems analysis course focusing on writing code.

All efforts were consolidated in the summer of 2004. Borrowing and refining materials from the capstone SDLC course, the two courses were merged into one course offered for twice the hours and taught by the same professor. 


\section{Key Success Factors}

The key success factors fall into two categories- those that helped bring the revision to fruition and those that apply to the success of the course.

The changes would not have happened were it not for the exceptional collegial atmosphere in the department that allowed faculty to open up their courses for inspection and revision in a supportive and non-threatening atmosphere. Even more impressive, the department took cues from its most junior faculty member who had extensive consulting experience.

An ASP.NET grant from Microsoft also helped fund the effort—especially the work that took place over the summer. However, the third key factor was the availability of the aforementioned student who helped to operationalize the redesign.

While the integrated course is still very much a work in progress, there are some good indicators of success. First, the quibbling by students about different standards being taught in the corequisites has been eliminated. One faculty member delivers a consistent methodology. Second, the students are handling problems of a much deeper scope. These projects mirror on a smaller scale the problems that students face in the capstone course. In fact the exact same SDLC methodology and deliverable set is used in both courses.

\section{Process of Delivering the Integrated Courses}

The integrated course is offered two days per week for 4 hours each day. The setting is a computerized classroom. The course consists of a sequence of mini-lectures supported by Microsoft PowerPoint which are followed by hands-on activities. Students are also given time in class to work on their individual and group projects. The course emphasizes systems concepts and database design concepts. The course has both technical and non-technical dimensions. Wherever possible visual programming tools are used to simplify the development process and thereby allow the tackling of more complex systems. Microsoft Access is used to develop the databases, while Microsoft Visual Studio is used to develop the user interface. The GUI of both software packages is highly exploited. Nonetheless SQL is taught in the database portion and some coding is added to the Visual Studio portion for those situations in which the visual IDE does not support the desired outcome.

\section{A Survey Study}

A survey was conducted at the end of the term to get student feedback. Items measured included attitudes towards the integrated course, perceived learning performance, learning process, communications with peers and instructor, and so forth. Due to the exploratory nature of this study, no comparison samples were used. Summary graphs of findings are shown below. 
Section A - 1. Your gender

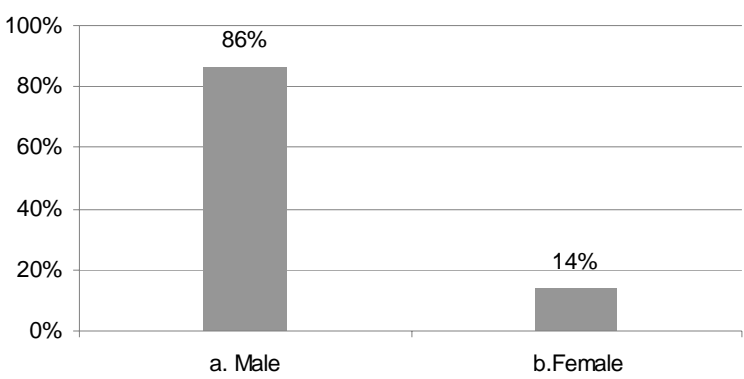

Section A - 3. Taking the integrated MIS320-380 course helped better understand how data base design is integrated with overall information system design and development.

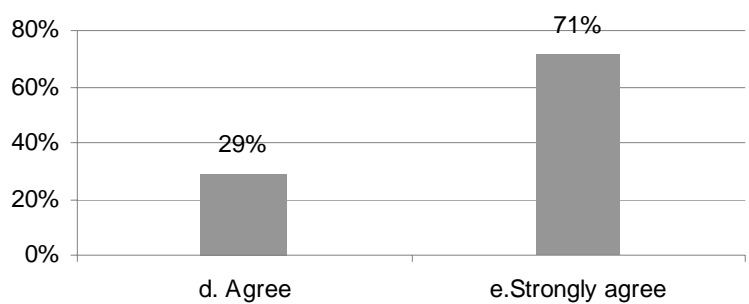

Section A - 5. Taking the integrated MIS320-380 course helped us get a better feeling of the systems development process in reality than separated courses.

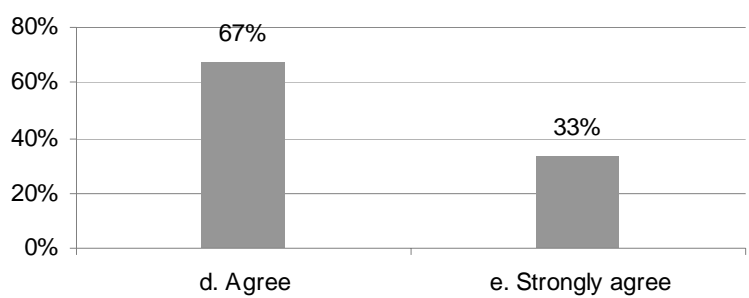

Section A - 7. I didn't have to work as hard for the integrated course.

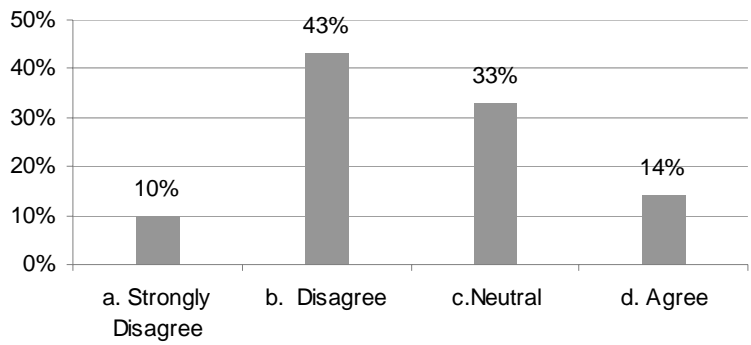

Section A - 2. Taking the integrated MIS320-380 course helped better understand about the links between the two courses.

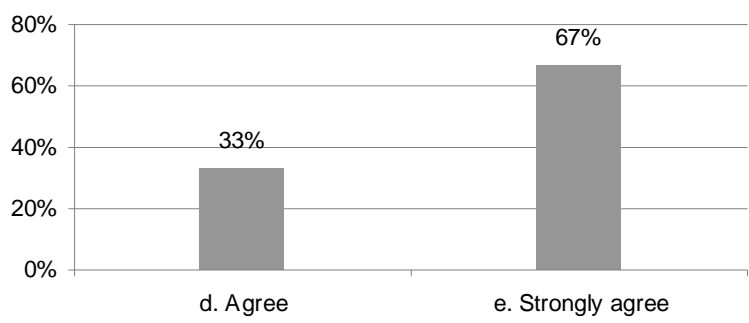

Section A - 4. Taking the integrated MIS320-380 course enabled us to do a more complicated systems analysis, design and development project, which is otherwise not possible in separated courses.

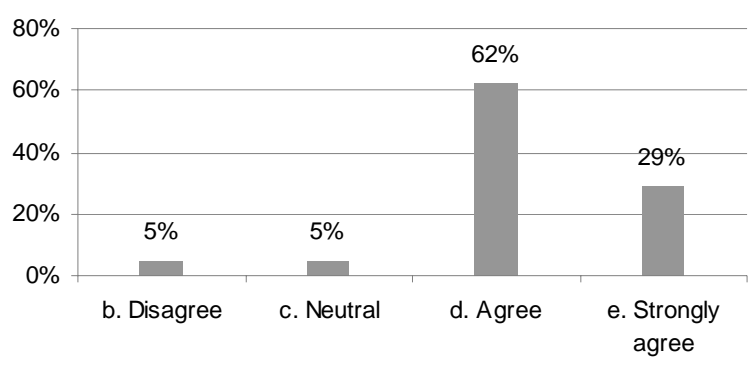

Section A - 6. I felt more "inhibited" in taking part in the discussion in the integrated MIS320-MIS380 course.

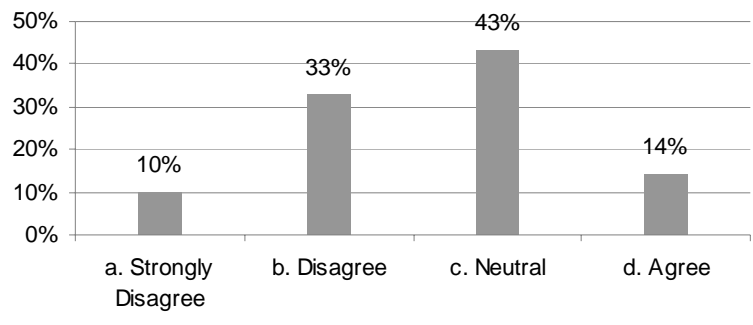

Section A - 8. I com municated more with other students in the integrated course.

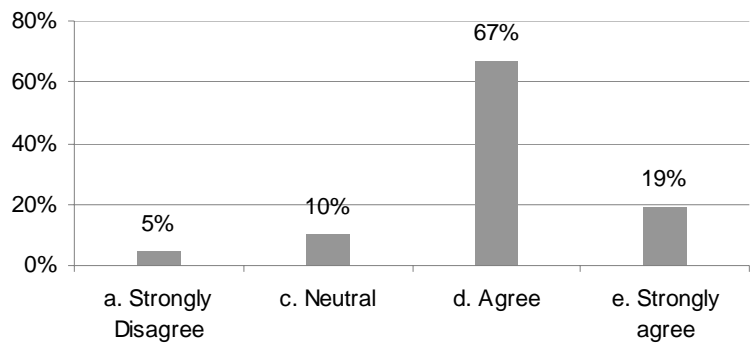


Section A - 9. More contact time in the integrated course made me feel closer to the instructor.

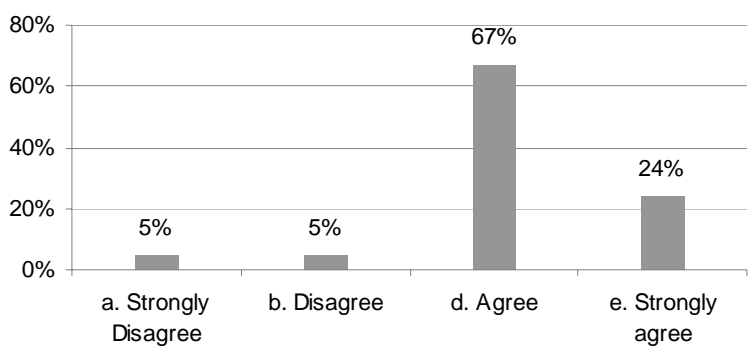

Section A - 11. I felt more "involved" in taking an active part in the integrated course.

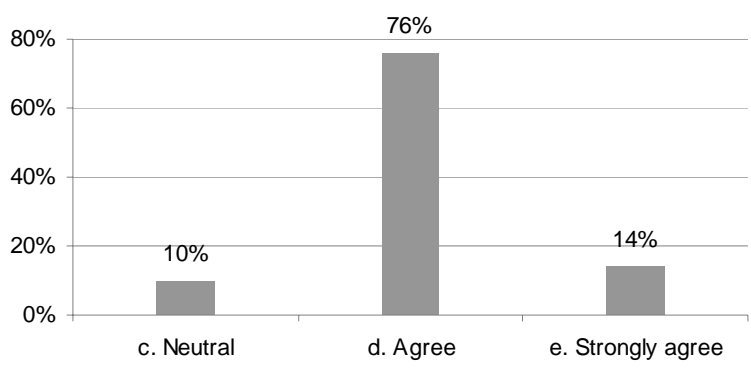

Section A - 13. I found the integrated course to be a better experience than traditional separated courses.

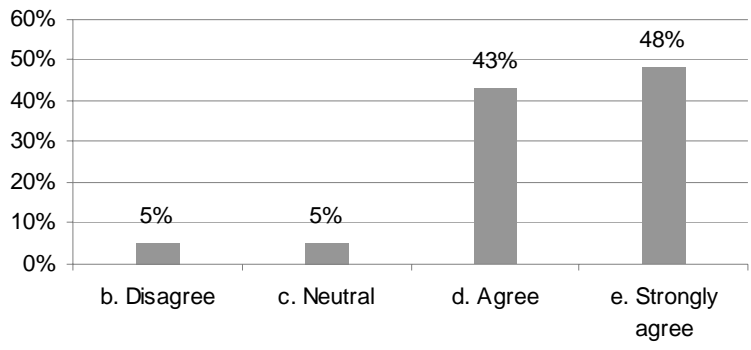

Section A - 10. The integrated course is more boring than separated courses.

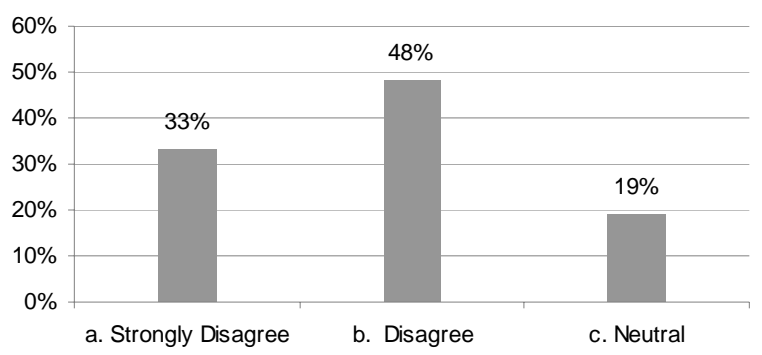

Section A - 12. I would NOT choose to take another integrated course like this.

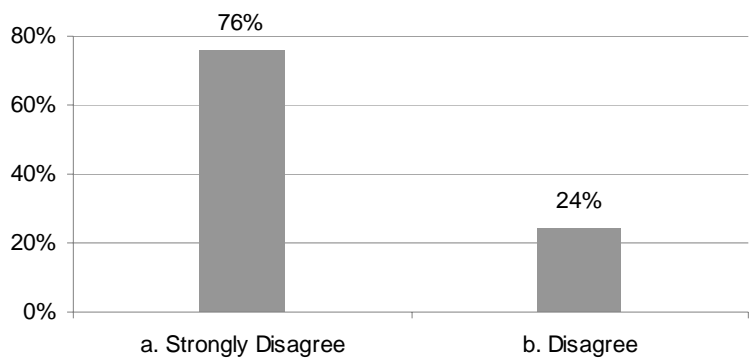

Section A - 14. I learned more in the integrated course than in traditional separated courses.

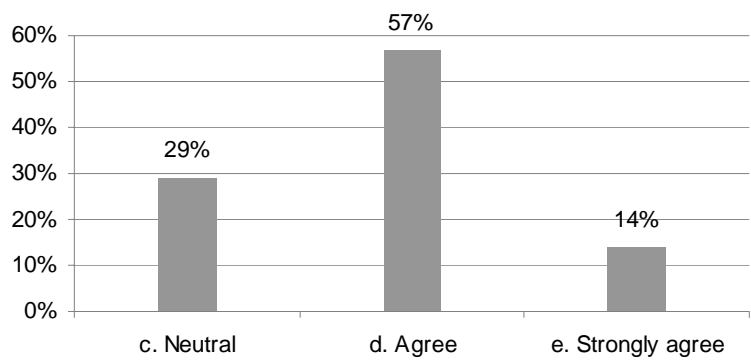

\section{Actual Learning Performance}

The professor of the follow-on capstone course reports that the students are better prepared for his course. The professor who taught the previously separated systems analysis and design course also reports that students in the integrated course learn more about systems development, and were able to tackle a larger and more complex systems development project during the course as well. The professor who taught the previously separated database management systems course reports greater understanding by the students of where database fits within systems and no loss of technical database learning outcomes. This is significant because database management systems was previously the more technical of the two courses. 


\section{DISCUSSION AND IMPLICATIONS}

While the revised course is still very much a work in progress, the department is very pleased with the initial success. The faculty are committed to continuing the process throughout the entire curriculum. The faculty believe that at a minimum the SDLC can appear in some form throughout the entire curriculum.

By far the most important success factor is collegiality. Collegiality leads to willingness to experiment and change. Collegiality leads to the acceptance of guidance from junior faculty and even students. Collegiality makes faculty want to work hard to accomplish significant results.

The other significant success factor is support. This may take the form of funding, student help, assistance from the technical staff, or recognition by the department chair. These are major efforts, and major efforts should be rewarded in tangible and intangible ways.

For the future it will be interesting to see whether the model can be applied to other courses. For example, can the networking course be combined with a programming course to form a course that centers around the development and implementation of ERP systems?

IS educators attempting curricular revisions should begin with a vision of the core competencies they are trying to develop in their students. This vision helps keep everyone on course during the redesign.

We are just beginning the redesign of our entire curriculum. It is an exciting adventure with a lot of hard work. However, the faculty are committed to adding value for our students. We will report more as the results become available.

\section{REFERENCES}

1. Alavi, M. \& Leidner, D. E. (2001) Research commentary: technology-mediated learning - A call for greater depth and breadth of research, Information Systems Research, 12(1), 1-10.

2. Frost, R. \& Pike, J. (2004). A revolutionary approach to introductory MIS: Professional, project Based, decision Focused, visual and engaging, Issues in Information Systems, 5(2), 454-460.

3. Hill, D.A. Scorpio - A system of medical teaching, Medical Teacher, 14(1), 37-41.

4. Hudson, J.N. \& Tonkin, A.L. (2004). Evaluating the impact of moving from discipline-based to integrated assessment, Medical Education, 38(8), 832-843.

5. Lanzilotti, S. S., Finestone, A.J., Sobel, E., \& Marks, A.D. (1986). The practice integrated learning-sequence - Linking education with the practice of medicine, Adult Education Quarterly, 37(1), 38-47.

6. Leidner, D. E., \& Jarvenpaa, S. L. (1995). The use of information technology to enhance management school education: A theoretical view, MIS Quarterly, 265-291.

7. Tritton, T.R. (2001). Integrated learning - Passing fad or foundation for the future?, Unity of Knowledge: The Convergence of Natural and Human Science, 935, 266-274. 